\title{
Geological Hazards: Programs and Research in the U.S.A.
}

\author{
by John R. Filson
}

Geological hazards have been studied for centuries, but government support of research to lessen their effects is relatively new. This article briefly describes government programs and research underway in the U.S.A. that are directed towards reducing losses of life and property from earthquakes, volcanic eruptions and landslides.

\section{Introduction}

Until recently, volcanic eruptions, earthquakes and major ground failures in populated regions have been viewed as natural disasters that were unpredictable and producing effects that were unavoidable. Research over the past few decades has led to an increased understanding of the effects and causes of geological hazards and to a widening recognition that measures can be taken to reduce their impacts on people and structures. Thus today, in the U.S.A. and elsewhere, formal government programs have been established to study these hazards, not only to explain and understand the phenomena themselves, but also to provide a basis for warning and mitigation strategies that will reduce losses and suffering.

\section{The National Earthquake Program}

Studies of earthquakes as a geological hazard in the U.S.A. are conducted under the aegis of the National Earthquake Hazards Reduction program (Hanks, 1985). This program was established by an act of Congress in 1977 for an initial three year period and it has been re-authorized either on an annual or biennial basis since 1980 following reviews by several Federal legislative committees. Four government agencies participate in the national program with approximate division of labor and funding (1987) shown in Table l.

The execution and coordination of a program of this scope present complex and challenging tasks, due primarily to the participation of several hundred scientists from government, academic and private sectors. All of the funds provided to the National Science Foundation (NSF) and about one quarter of those provided to the USGS are used to support research at universities, at state and local government agencies, or elsewhere in the private sector. Because of the high national interest in the program and because of its "mission" orientation, research support must be justified in terms of leading to an increased understanding of the causes or effects of earthquakes or to an application that will reduce earthquake hazards.

Research within the earthquake program on geological and geophysical topics is carried out through NSF and the USGS (Table 1) and can be classified under four general headings: basic research on plate tectonics and the earthquake process, research on estimating the earthquake potential of a region, prediction, and studies of effects or hazards assessments. All of these elements are linked with the basic research providing a framework upon which statements of long-term earthquake potential or forecasts can be made. These in turn form the basis for concentrated prediction experiments and assessments of the effects of earthquakes in a given region.

\section{Earthquakes and Their Sources}

The current emphases in fundamental research are in modelling the earthquake source and in determining the physical properties and structure of the continental lithosphere. Seismic waves observed at great distances from the source and recorded digitally are now collectively and routinely analyzed to provide not only the location and magnitude of the source event but also its "moment tensor," a mathematical representation of the displacement field at the source. This information is of great use in determining the active tectonics of an earthquake-prone rezion (Fig. 1, and see Crowell, this issue).

Table 1: The National Earthquake Hazards Reduction Program

Federal Emergency Management Agency (\$6 million)

- Lead agency

- Preparedness planning and hazard awareness

U.S. Geological Survey ( $\$ 35$ million)

- Hazard Delineation and Assessment

- Earthquake Prediction Research

- Data and Information Services

National Science Foundation ( $\$ 28$ million)

- Research on plate tectonics and earthquake processes

- Seismic design and engineering research

- Societal response research

National Bureau of Standards ( $\$ 0.5$ million)

- Development of design practices and manuals

The Incorporated Research Institutions for Seismology (IRIS), with primary support from NSF and in cooperation with the USGS, are currently involved in the worldwide deployment of a new generation of digitally recording seismographs and in the development of portable seismometer arrays. These efforts will result in a significant increase in the data available for earthquake source and Earth structure studies. At locations very near the earthquake source, records of strong ground shaking show the details of how a fault breaks or ruptures in an earthquake; this detail is important in developing earthquake resistant design and construction practices. Considerable attention is now being given to field studies to record strong ground shaking, and on theoretical research to explain these records and to predict the nature of the shaking that may be experienced at any given site. 
The NSF and the USGS continue to conduct active seismic experiments using reflection and refraction techniques in transects across tectonically active areas. These surveys provide a structural framework for models of the Earth's crust in tectonically active regions. A consortium of universities for Deep Observation and Sampling of the Earth's Continental Crust (DOSECC 1987), again with primary support from NSF and with USGS cooperation, is drilling a hole to over 16,000 feet on the San Andreas fault at Cajon Pass just north of San Bernardino, California, to sample the rocks and physical properties near seismogenic depths and to resolve controversy over the state of stress on the fault.

\section{Regional Potential for Earthquakes}

One of the more unexpected and dramatic results from research supported by the national earthquake program has been in the development of long-term forecasts concerning the earthquake potential of a region. Such forecasts serve as a basis for more specific, shorter term earthquake predictions and for guiding mitigation and preparedness measures. These forecasts are based on analyses of data from dense regional seismograph networks and from detailed studies of the Holocene geology in and near fault zones. The latter geological studies, in particular, have proved most rewarding and have given rise to a new field of geology termed "paleoseismology."

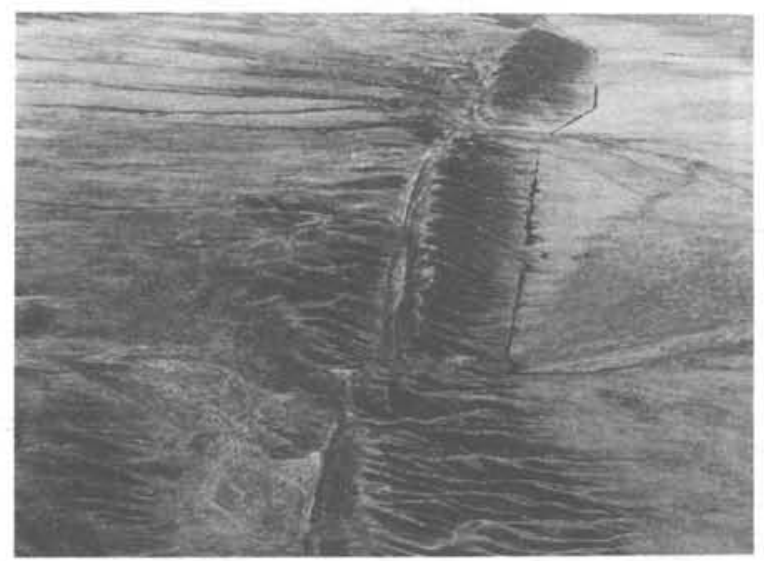

Figure 1: The San Andreas fault trace in central California. USGS photo.

Large-scale mapping of fault zones and excavations across fault traces have allowed geologists to estimate how often significant, pre-historic earthquakes occur in the zone, what the slip has been across the fault during these events and, by using various dating methods, when these earthquakes occurred. In some areas detailed mapping has allowed numerous fault trace segments to be identified within a fault zone. The dense networks of seismometers provide the data that are needed to determine which of these segments are active currently. When the geological and seismological data are combined they can, in some areas, be used to provide statistical statements on the likelihood of future earthquakes. This has been done for major branches of the San Andreas fault zone in California and the Wasatch fault zone in central Utah. Studies are underway to refine these estimates and to apply the techniques to other regions such as the Pacific Northwest, central and southeastern U.S.A., and Alaska.

\section{Predicting Earthquakes}

Earthquake prediction research has the goal of providing a short-term (hours to days) warning of damaging earthquakes in terms of their expected time, place and magnitude. In the early 1970 s, due to reports of successful predictions, it was thought by some that reliable earthquake prediction procedures could be established and in general use within a decade. The stated goal has proved elusive and more difficult to achieve than initially perceived; in retrospect this is not hard to understand. Moderate to large earthquakes are relatively infrequent events even in earthquakeprone areas.

To establish what physical changes or precursors can be observed prior to such events, arrays of sensitive instruments must be in place within the epicentral zone and maintained until an event occurs. It may be decades before this happens along a particular fault; because resources are limited, not all areas where earthquakes might occur can be monitored with the instrumentation required. It is now recognized that earthquake prediction research requires a long-term commitment of support for patient monitoring efforts.

In recent years the approach taken by the prediction program in the U.S.A. has been to carry out laboratory and theoretical studies on the mechanics of fault rupture to gain insight into what physical properties of the fault zone might change prior to an earthquake, to design instruments to reliably measure these properties, and to place such instruments in dense arrays in areas where moderate to large earthquakes are expected. Studies of earthquake potential of the San Andreas fault zone have revealed that the fault segment near Parkfield (Fig. 2) in central California breaks about once every 22 years in a moderate (magnitude about 6) earthquake. The last earthquake here occurred in 1966.

During the past two years, in cooperation with the State of California and with the participation of scientists from several universities, the USGS has installed a comprehensive suite of instrumentation over a $30 \mathrm{~km}$ long segment of the fault near Parkfield. A formal, long-term forecast of the earthquake has been made along with a commitment to provide a short-term warning if possible. To this end, decision criteria for issuing a short-term prediction have been established, and plans for dealing with the warning have been set in place by local officials. In addition to the Parkfield area, other regions, primarily in the western U.S.A., are monitored in a similar although more dispersed manner with seismometer and geodetic networks.

\section{The Effects of Earthquakes}

Research on assessing earthquake hazards involves predicting the effects expected in a given region. These include ground shaking, ground surface breakage due to fault

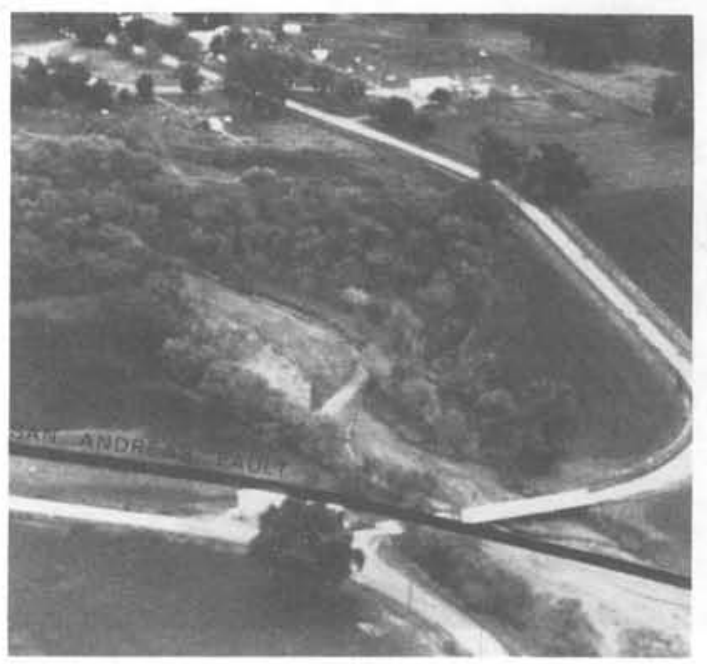

Figure 2: Aerial view of Parkfield, California (population - 34). 
rupture, and ground failure due to landslides, slumps, and liquefaction. Research on these topics can be basic, such as investigating the general properties and causes of these effects, or applied and specific, estimating, for example, the severity of these effects for a given region. In recent years, because of increased understanding of the tectonic setting and geology of several seismic areas, research has tended to become more specific and directed toward regional assessments.

Most of this research is carried out or supported by the USGS. The general plan has been to spend three to five years of concerted effort in assessing the earthquake hazards in a region containing a large urban population. Included are several workshops and meetings to coordinate the efforts of the researchers involved and of local officials who may be expected to act on or implement the results, which are set down in a final, comprehensive report. Studies have so far been completed in the San Francisco and Los Angeles areas of California and the Wasatch Front region of Utah and are underway in the western portions of Oregon and Washington.

Although generally described as applied research, each regional hazard assessment offers unique challenges and opportunities for basic research to those involved. For example, in assessing the earthquake hazards of the Pacific Northwest one of the fundamental problems is estimating the magnitude of the largest earthquake to be expected. No large earthquake along the nearby Juan de Fuca subduction zone has been recorded in historical time; however, similar zones elsewhere have given rise to magnitude 8 events and larger. There is geological evidence of large changes in sea level along the coast of Washington during the Holocene that may be associated with major, plate-boundary earthquakes. Geodetic surveys indicate that strain is accumulating in the region. There is other evidence that aseismic slip is accounting for much of the relative plate motion along the subduction zone. This matter is under intensive investigation and is typical of fundamental questions that arise in regional hazards assessments.

\section{The Volcano Studies Program}

The volcano hazard program is considerably more modest than the earthquake effort. This program received about $\$ 11$ million in support in 1987 and is carried out almost entirely within the USGS. Research supported by NSF

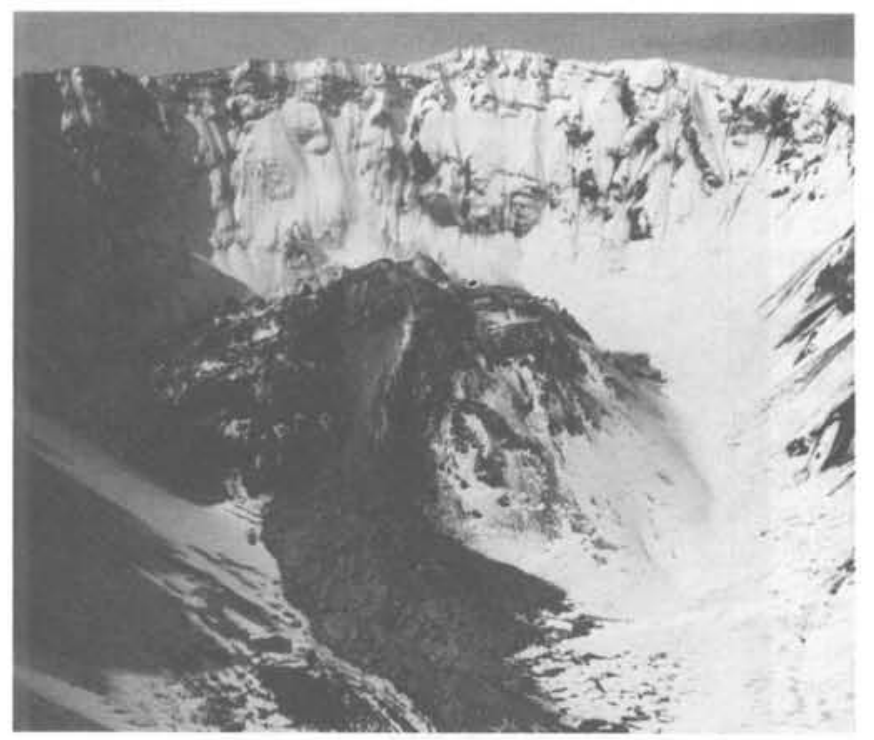

Figure 3: The dome in the crater of Mount St. Helens in May 1986. Photo by Lyn Topinka. addresses volcanological topics in general but is not directed towards, or justified by, reducing hazards from voleanic eruptions. Within the USGS it is recognized that a substantial fraction of volcano hazards are water-related, either due to rapid melt of ice or snow pack, or to rapid influx of sediment (ash) into the local drainage system, or both. Accordingly, about one-third of the volcano hazards research conducted by the USGS is on water-related phenomena.

The research supported by the volcano hazards program can be classified under three broad headings: fundamental studies of volcanic processes, volcano hazards assessments, and volcano monitoring. The USGS maintains the Hawaiian Volcano Observatory near the summit of Kilauea on the island of Hawaii and the Cascades Volcano Observatory at Vancouver, Washington. Although both observatories have the primary purpose of monitoring the activity of nearby volcanoes, each serves as a support base for basic research and hazard assessments.

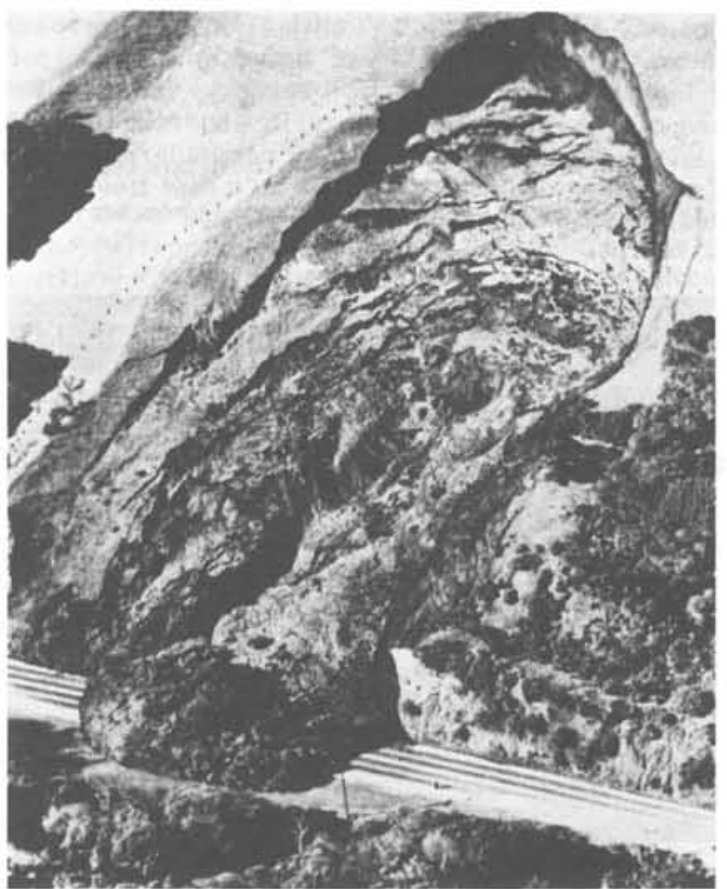

Figure 4: Landslide on Highway 24, east of Oakland, California. USGS photo.

\section{Studying Volcanic Processes}

Research on volcanic processes attempts to lay the foundation for the hazards assessment and monitoring efforts. The goal is to increase the understanding of the evolution of magmatic bodies, of how magma moves in the Earth's crust from these bodies, and of how the physical and chemical conditions give rise to eruptions. Topics covered range from igneous petrology to field geodetic surveys and include the effects of tidal influence on eruptive cycles and historical surveys of activity at young calderas worldwide (Souther et al., 1984). The latter study is of particular significance in assessing the liklihood of a period of unrest (uplift and seismic activity) within a caldera evolving into an eruptive phase. Seismic studies on the origin and nature of volcanic tremors and on the extent and structure of magma reservoirs are included in the research on volcanic processes.

\section{Assessing Volcano Hazards}

As in the case of earthquakes, great progress has been made in recent years in volcano hazards assessment through detailed geological studies of Quaternary deposits. These studies have revealed not only the frequency and time of 
eruptions in the recent past, but also the nature of the eruptive material and the extent of air and water-born deposits. A systematic study of the hazards associated with voleanoes in the Cascade Range of the Pacific Northwest has been underway for several years and reports have been released on seven volcanic centers there.

The report on Mount St. Helens is notable in that it was first published in 1978, two years before the catastrophic eruption of May 1980. The report (Crandell and Mullineaux, 1978 ) identified this as one of the more dangerous volcanoes of the Cascade Range and predicted many of the effects of the May 1980 eruption. From a hazards assessment perspective, the recent eruption of Mount St. Helens provided a wealth of scientific information that has already been applied to the interpretation or reinterpretation of volcanic terranes in the northwestern U.S.A. and elsewhere. Additional work is in progress on the Hawailan Islands and on the Cook Inlet volcanoes of Alaska.

\section{Monitoring Volcanoes}

The Hawailan Volcano Observatory and the Cascades Volcano Observatory each have a permanent staff of about twenty people who maintain surveillance over volcanoes in the region to provide advanced warning of an eruption and continuous monitoring and evaluation of an eruptive phase. The observatories serve as analysis centers for seismic, geodetic, geochemical, petrological, and other types of data and as points of contact and information for civil defense officials and the public in general.

The observatory on Hawaii was established in 1912 and in 1987 celebrated its 75 th anniversary with a symposium on "How Volcanoes Work" and with the publication of a twovolume collection of papers on the volcanism of Hawaii (Decker et al., 1987). Both the observatories have been quite active during the past few years, with Kilauea in eruption since 1983 (see cover photo and article this issue by Tilling) and continued growth of a dome within the explosion crater of Mount St. Helens (Fig. 3).

Monitoring efforts are also currently being carried out in an ancient caldera at Long Valley on the eastern flank of the Sierra Nevada Mountains in central California and on Augustine Volcano in Cook Inlet of southeast Alaska. The USGS cooperates with the University of Nevada and the University of Alaska, respectively, in these efforts.

\section{Landslide Studies}

With an annual funding of about $\$ 2$ million, the landslide program is the smallest of the three geological hazards programs within the USGS. Although it is estimated that landslide losses in the U.S.A. exceed $\$ 1$ billion annually, these losses are usually so dispersed they do not attract the national concern that they deserve. Recent exceptions to this statement include a major slide near Ponce, Put to Rico, that killed 130 people, a series of landslides and debris flows in 1983 and 1984 in Utah that were triggered by unusually heavy and concentrated spring run off, and a series of slope failures and flows in the central coast region of California triggered by heavy winter storms in 1982 and 1983.

The research supported by the landslide program can be grouped under three general topics: landslide processes, landslide prediction, and inventory and susceptibility studies. The chief efforts on processes are in field studies of recent and active slide areas (Fig. 4) and in theoretical studies of soil and rock mixtures under the influence of gravity and of varying degrees of saturation. Physical parameters in a debris flow area near La Honda, California, are being monitored in a pilot experiment to provide shortterm warning to populated areas down slope of the activation of a flow.
Larger-scale studies in the San Francisco Bay area of California are monitoring rainfall and soil saturation conditions. This area is subject to intense winter storms that can release several inches of rain within a few hours, triggering in turn landslides and debris flows. Based on these studies and a forecast of heavy rains, the first formal public warning of landslide activity in the U.S.A. was issued in a joint USGS-National Weather Service announcement in February 1986 (see Keefer et al. 1987).

Landslide inventories and susceptibility mapping are analogous to the regional earthquake and volcano hazards assessments described above. The landslide inventories are usually carried out in cooperation with state organizations and form the basis for state and regional landslide susceptibility mapping. Major innovations are occurring in the preparation of susceptibility maps through digital methods and the use of computer-based Geographic Information Systems. Digital data bases with geological, topographic, ground cover, rainfall, and other spatial information are compiled and compared with the digital landslide inventories. Analytical procedures are then used to determine what set of conditions have given rise to landslides in the past and to project which additional regions will be susceptible to landslides in the future. The susceptibility maps are simply "hard copies" of digital files based on these inventories and analytical procedures.

\section{Summary}

These programs in geological hazards research are new and somewhat pioneering. They represent efforts to apply geological knowledge to enhance public safety and to reduce property losses from geological hazards. The "pay-off" in these programs is often neither immediate nor obvious, and support is thus often difficult to maintain. Reducing public risk through assessing or predicting geological hazards involves professional risk taking by earth scientists. In some cases they are asked to make judgements based on very subtle evidence and sparse data, but upon which lives may depend and public safety policy may be developed. In general, however, geological hazards assessments and prediction research have yielded exciting scientific results and rewarding public and professional recognition for those in the U.S.A. working in these fields.

Dr. John R. Filson is Chief of the Office of Earthquakes, Volcanoes, and Engineering of the U.S. Geological Survey (905 National Center, Reston, VA 22092, U.S.A.). The office has about 800 employees who work on geological hazards, geothermal resources and the geomagnetic field. Dr. Filson is Vice-Chairman of the National Earthquake Prediction Evaluation Council.

\section{References}

Crandell, D.R. and Mullineaux, D.R., 1978. Potential Hazards from Future Eruptions of Mount St. Helens volcano, Washington. U.S. Geological Survey Bulletin no.1383-C, 26p.

Decker, R.W., Wright, T.L. and Stauffer, P.H. (ed.), 1987. Voleanism in Hawail. U.S. Geological Survey Professional Paper 1350, 1667p.

DOSECC, 1987. DOSECC continental scientific drilling program, EOS, May 26,1987 , p. $545-6$.

Hanks, T.C., 1985. The National Earthquake Hazards Reduction Program scientific status. U.S. Geological Survey Bulletin 1659, 40p.

Keefer, D.K. et al., 1987. Real-time landslide warning during heavy rainfall. Science, v. 238, p 921-925.

Souther, J.G., Tilling, R.I., and Punongbayan R.S., 1984. Forecasting eruptions in the circum-Pacific. Episodes, v. 7, no. 4, p 10-18. 


\section{Exploration results in real time, not overtime}

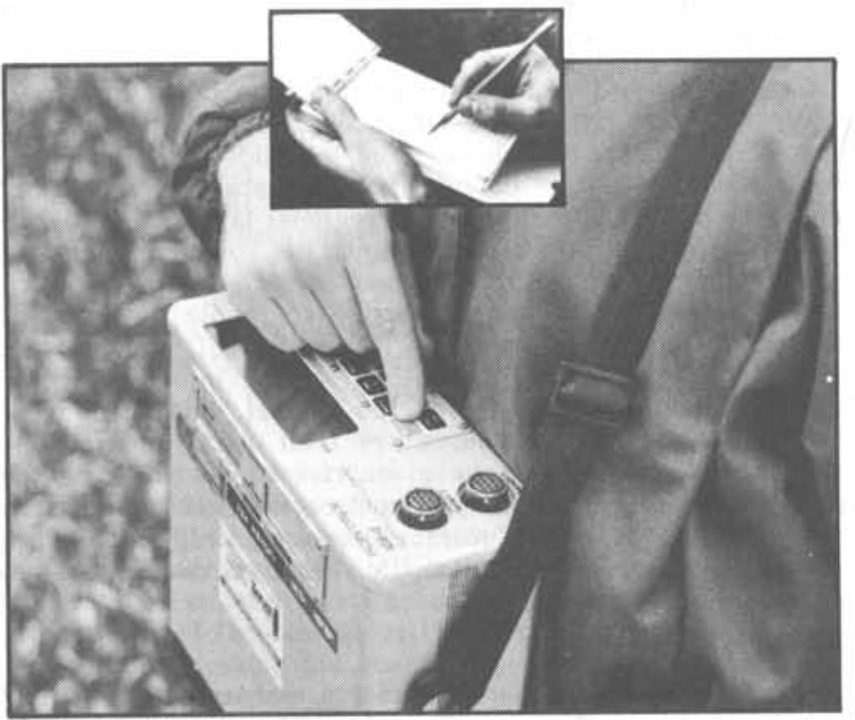

Electronic notebook saves writing

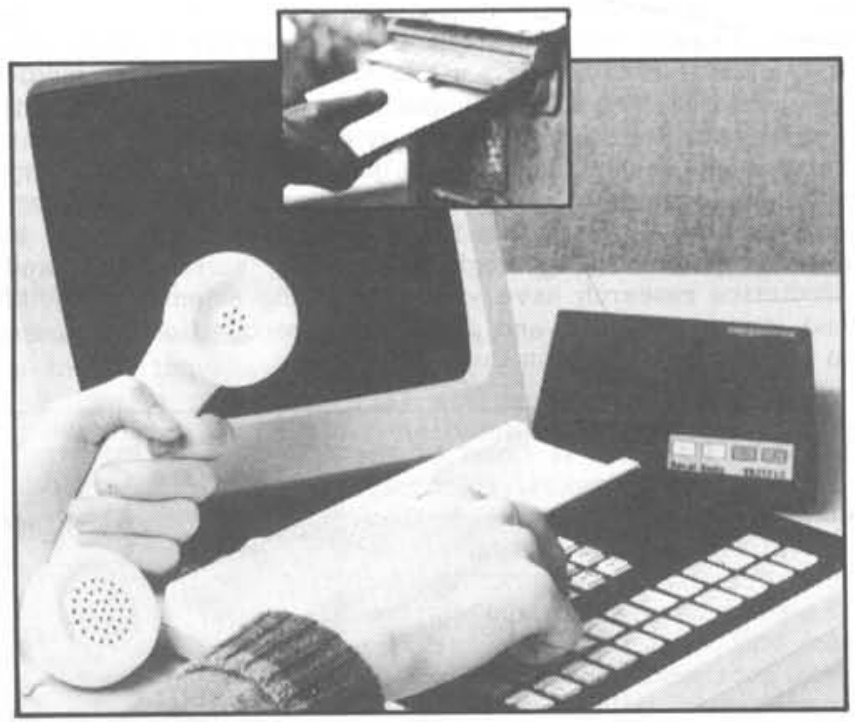

Don't mail data, phone it

Every explorationist knows the old way of getting the geophysical facts. You juggle your instrument, pencil and notebook. estimate an average value and write it down. Later, into the night, you sit in your camp manually calculating and plotting your findings.

Sure it works. But why waste time? Why make human errors? Instead, use the Scintrex IGS Integrated Portable Geophysical System. It will automatically stack, average, statistically qualify, calculate and compare present with previous data. You just check values on a display. If you accept them, you press a key and they are locked in memory. At the end of the day, connect the IGS to a digital printer and watch it list the data or even plot profiles.

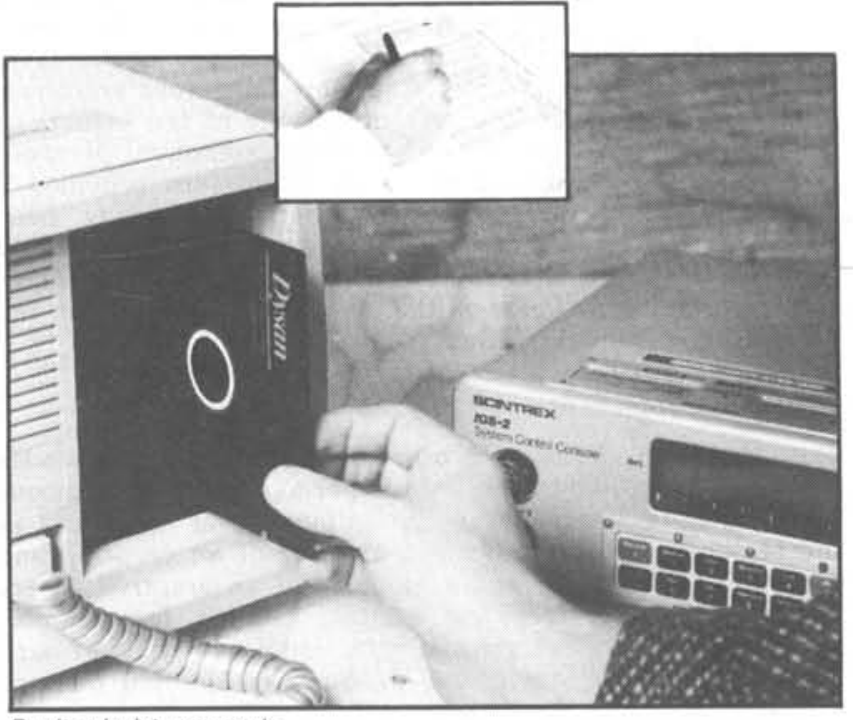

Don't calculate, compute

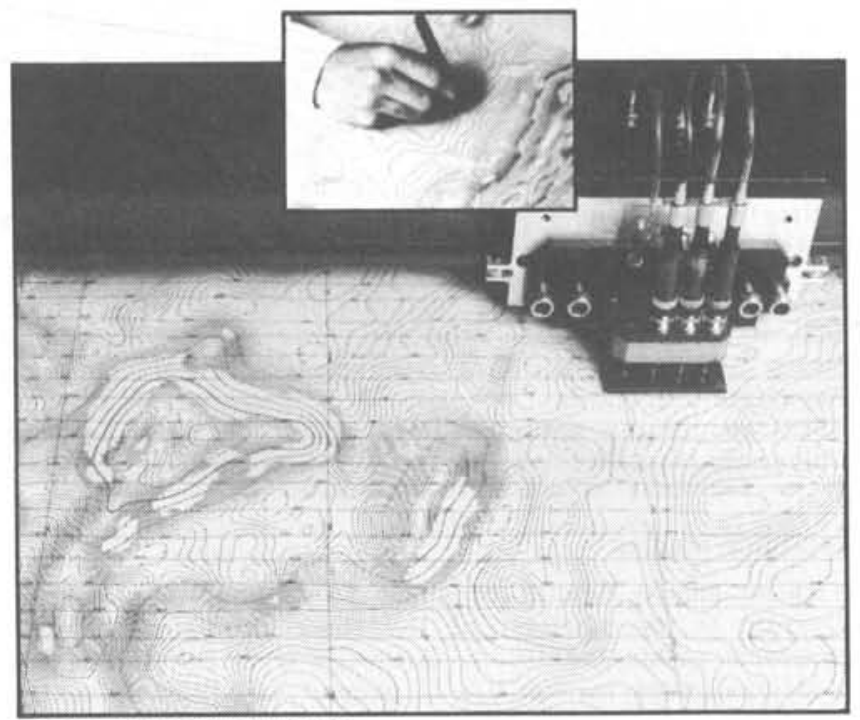

Let a computer push your pen

Then you can access your computer, either directly in the fielc or over telephone lines to your office. Your final maps and computer assisted interpretation will be prepared effortlessly, the same day.

What you're doing is using real time, computer as-it-happens time, instead of overtime.

The benefits are obvious - Better data! Money saved! Try it once and you'll never go back to the old way.

For full information on what Scintrex microprocessor-based, computer compatible instrumentation can do for you in magnetics, VLF, EM or IP, contact Scintrex at 222 Snidercroft Road, Concord, Ontario, Canada L4K 1B5, telephone (416) 669-2280, telex 06-964570.

\section{SCINTAEX}

